TAO, Vol. 16, No. 2, 377-391, June 2005

\title{
Volume Transport Through the Taiwan Strait: A Numerical Study
}

\author{
Chau-Ron $\mathrm{Wu}^{1,{ }^{*}}$ and Yi-Chia Hsin ${ }^{1}$ \\ (Manuscript received 21 October 2004, in final form 6 March 2005)
}

\begin{abstract}
A fine grid resolution model with realistic bathymetry was constructed to study the spatial and temporal structures of flow through the Taiwan Strait where observations are limited. The model covers an expanded domain that includes the entire East China Sea and South China Sea, as well as the region occupied by the Kuroshio. The fine-resolution model derives its open boundary conditions from a larger scale Western Pacific Ocean model. Two numerical weather products from the European Center for Medium-Range Weather Forecasts and National Centers for Environmental Prediction, and one satellite observation-based wind set (QSCAT) are used to force the ocean model. Model experiments suggested that the best simulation is achieved when the model is driven by the QSCAT wind forcing. Several important features are reproduced in the model simulation. The volume transport is northward and largest in summer while minimal volume transport is southward and occurs in fall and winter. The general trend of volume transport is related to the seasonal reversal of monsoon winds. The present model also suggests that flow in the entire Taiwan Strait is to the southwest during periods of strong northeasterly wind. The annual average transport based on the present model is $1.09 \mathrm{~Sv}\left(1 \mathrm{~Sv}=10^{6} \mathrm{~m}^{3} \mathrm{~s}^{-1}\right)$, which is smaller than most published values based on shipboard Acoustic Doppler Current Profiler (sb-ADCP) observations. The result suggests that sb-ADCP observations are biased toward estimates in summer and fair weather since bad weather during the winter northeast monsoon often prevents seagoing observations.
\end{abstract}

(Key words: Volume transport, Taiwan Strait, Penghu Channel, Numerical modeling)

\footnotetext{
${ }^{1}$ Department of Earth Sciences, National Taiwan Normal University, Taipei, Taiwan, ROC

* Corresponding author address. Prof. Chau-Ron Wu, Department of Earth Sciences, National Taiwan Normal University, Taipei, Taiwan, ROC; E-mail: cwu@cc.ntnu.edu.tw
} 


\section{INTRODUCTION}

The Taiwan Strait connects the South China Sea with the East China Sea. The orientation of the strait is approximately southwest to northeast. Except for the deep Penghu Channel in the southeastern corner, the Strait is generally shallower than $60 \mathrm{~m}$ (Fig. 1b). Several studies suggested that the Taiwan Strait, although shallow, is essential to material transport in and out of the East China Sea. For example, Huh and Su (1999) reported that the Taiwan Strait transport contributed about one third of the total sediment input into the East China Sea. Liu et al. (2000) found that the transport through the Taiwan Strait plays a major role in the circulation and nutrient balance over the East China Sea. Isobe (1999) pointed out that the Tsushima Current originates from the Taiwan Strait year round except during fall.

Despite the importance of mass flux through the Taiwan Strait, data from direct current measurements are limited. Composite velocities obtained from shipboard Acoustic Doppler Current Profilers (sb-ADCP) between 1990 and 2001 indicate northward flow in the Taiwan Strait year round (Liang et al. 2003). Southward flow during prevailing northeasterly wind occurred occasionally in the data of a moored current meter deployed in the Penghu Channel
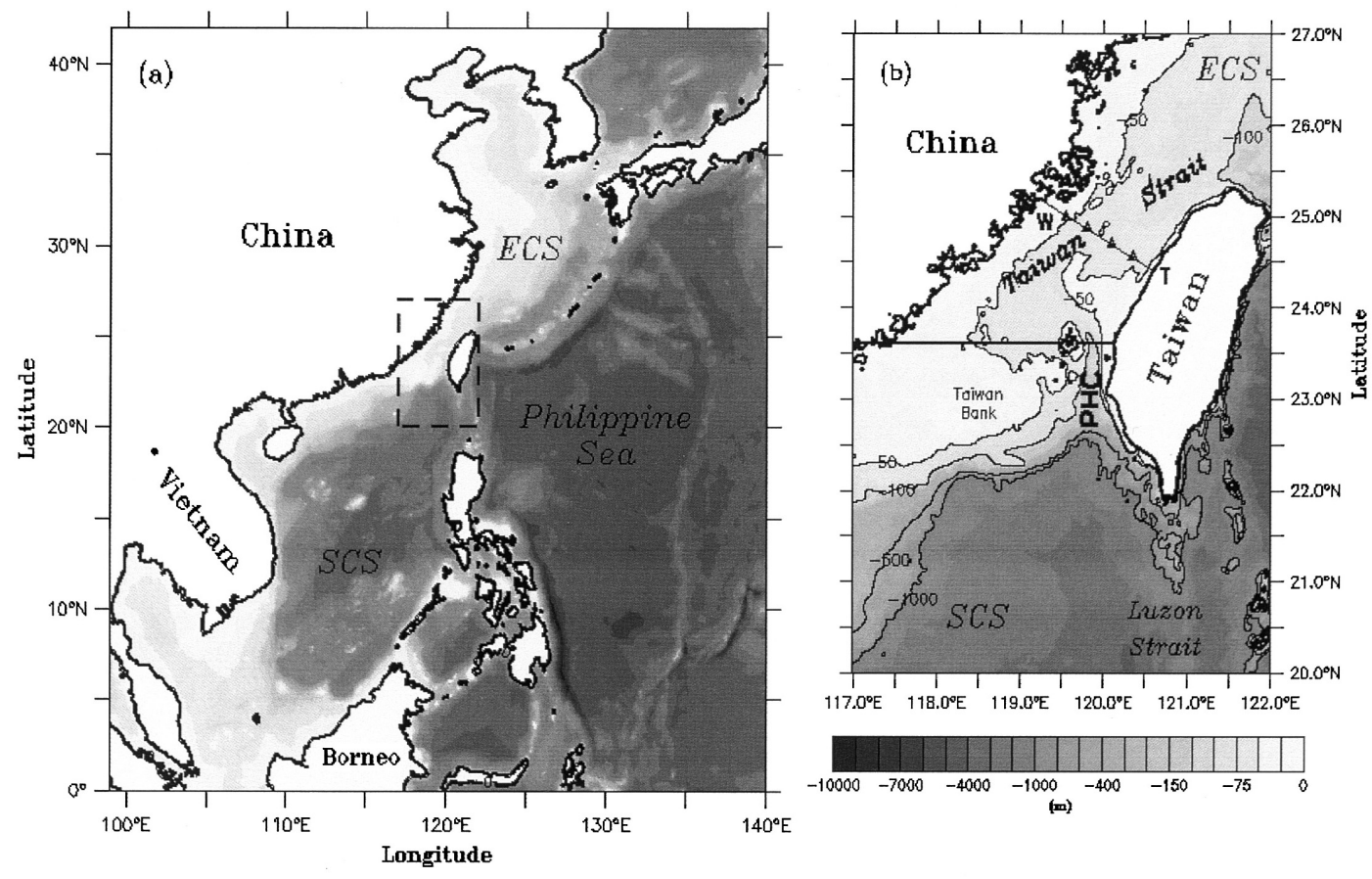

Fig. 1. (a) The integrated domain of the EAMS model with realistic bathymetry. (b) The study area with locations of mooring stations (triangles) and the Penghu Channel (PHC). The horizontal line across the PHC Island is chosen to calculate the strait-wide volume transport from model. 
between March and October (Chuang 1985, 1986). On the other hand, from the distribution of water properties, Chen (2003) argued that water in the Taiwan Strait in winter should be predominantly from the East China Sea. Northward flow occurs in winter only during sudden relaxation of the steady northeasterly wind. Recent bottom-mounted ADCPs deployed in the Taiwan Strait from October to November 1999 further demonstrated that strong southwestward flow could occur during strong northeasterly wind bursts at a biweekly period (Teague et al. 2003; Ko et al. 2003).

Based on the analysis of 2.5-year (1999-2001) sb-ADCP data, Wang et al. (2003) provided quantitative estimates for the mean current and total transport through the Taiwan Strait. The average velocity is about $0.40 \mathrm{~m} \mathrm{~s}^{-1}$, and the mean transport through the Taiwan Strait is northward at $1.8 \mathrm{~Sv}\left(1 \mathrm{~Sv}=10^{6} \mathrm{~m}^{3} \mathrm{~s}^{-1}\right)$. They also pointed out that the maximum seasonal transport occurs in summer at $2.7 \mathrm{~Sv}$, northward. The minimum transport is in winter, at $0.9 \mathrm{~Sv}$ northward. Wyrtki's (1961) bimonthly transport estimates are $0.5 \sim 1.0 \mathrm{~Sv}$ northward in summer, $0.5 \mathrm{~Sv}$ southward in fall and winter, and $0.0 \mathrm{~Sv}$ in spring. Although the annual mean transport of $1.8 \mathrm{~Sv}$ by Wang et al. (2003) is different from the earlier estimate of $0.0 \mathrm{~Sv}$ by Wyrtki (1961), the ranges of seasonal variation $(\sim 1.7 \mathrm{~Sv})$ in these two estimates are similar. Recent sb-ADCP observations showed that the northward flow through the Penghu Channel, the only deep passage in the Taiwan Strait, is the major pathway for flow in the Taiwan Strait (Jan and Chao 2003). The volume transports through the Penghu Channel calculated by Jan and Chao (2003) are $-0.11 \sim 0.02,0.56 \sim 1.10,1.26 \sim 1.72$ and $0.76 \mathrm{~Sv}$ in winter, spring, summer and fall, respectively. The strong seasonal variability with generally northward transport is evident both in the Taiwan Strait and the Penghu Channel (Jan and Chao 2003). Nevertheless, these transport estimates are based on data of limited spatial and temporal coverage. It seems necessary to use new-generation models with realistic forcing and higher resolution to provide better estimates for the transports through the Taiwan Strait.

In this work, we study the volume transport through the Taiwan Strait using the Princeton Ocean Model (POM, see section 2 for details) with realistic topography and forcing at a horizontal resolution of $1 / 8^{\circ}$ embedded in an expanded domain model. The expanded domain eliminates the ambiguities in the upstream boundary conditions. The primary objective of this study is to describe volume transports through the Taiwan Strait and Penghu Channel. We will also attempt to relate the model results to observations.

\section{THE NUMERICAL MODEL}

The East Asian Marginal Seas (EAMS) model used here is a sigma-coordinate version of the Blumberg and Mellor (1987) hydrodynamic model. The three-dimensional, free surface model solves the primitive equations for momentum, salt and heat. It includes a 2.5-level turbulence closure sub-model developed by Mellor and Yamada (Mellor and Yamada 1974; Mellor and Yamada 1982) and the Smagorinsky formulation for horizontal mixing (Oey et al. 1985). Additional information on the model can be found in Blumberg and Mellor (1987). The domain of the EAMS model with realistic bathymetry is presented in Fig. 1a. The horizontal grid size is $1 / 8^{\circ}$ and there are 26 sigma levels in the vertical. On the open boundaries, the 
EAMS model derives its boundary condition from a larger-scale West Pacific Ocean (WPO) model. The WPO model is based on the Miami Isopycnic Coordinate Ocean Model (MICOM) and has a horizontal resolution of $1 / 4^{\circ}$ and 15 isopycnic layers (Liang 2002). The WPO model domain extends from $95^{\circ} \mathrm{E}$ to $160^{\circ} \mathrm{N}$ in longitude, and from $20.8^{\circ} \mathrm{S}$ to $45.1^{\circ} \mathrm{N}$ in latitude. The WPO model driven by monthly climatological fluxes from the European Center for MediumRange Weather Forecasts (ECMWF) is first spun up for 10 years from rest and then continuously forced using 1996 - 2003 ECMWF daily wind data. A detailed description of the WPO model has been given by Liang (2002).

The Blumberg and Mellor model uses the mode splitting technique, in which the separation of the vertically integrated governing equations (barotropic, external mode) and the equations governing vertical structure (baroclinic, internal mode) are used. Boundary conditions are formulated for the barotropic and baroclinic modes separately and then adjusted to take into account the different truncation errors for those modes (Blumberg and Mellor 1987). The one-way coupling between the EAMS and WPO models is described below. The barotropic, vertically averaged velocities on the open boundaries of the EAMS model were estimated by the Flather (1976) formulation:

$$
\bar{u}_{n}=\bar{u}_{n}^{0}+\sqrt{\frac{g}{H}}\left(\eta-\eta^{0}\right),
$$

where $\bar{u}_{n}$ is the vertically averaged outward normal component of the velocity on the open boundary of the EAMS model at time $t, \bar{u}_{n}^{0}$ is the vertically averaged normal component of the velocity on the open boundary at time $t$ estimated from the WPO model. The model sea surface height $\eta$ is calculated from the continuity equation and is located half of a grid inside of the open boundary in the EAMS model domain. The WPO model sea surface height $\eta^{0}$ is located on the open boundary of the EAMS model. The water depth on the open boundary is $H$, and $g$ is the gravitational acceleration. An adjustment procedure was used to balance the net transport from the WPO model with the associated variation of sea surface height. Outputs from the WPO model have daily records of sea surface height and transports, which were interpolated to the EAMS grid using bivariate interpolation and to the EAMS model time step linearly in order to form $\eta^{0}$ and $\bar{u}_{n}^{0}$ in Equation (1). As a result, there is a lack of continuity between the total transport through the open boundaries estimated from $\bar{u}_{n}^{0}$ and the total change in the sea surface height of the modeling area estimated from $\eta^{0}$. A value, inversely proportional to the water depth on the open boundaries, was added to $\bar{u}_{n}^{0}$ along the open boundaries to balance the transport.

Baroclinic velocities on the open boundaries of the EAMS model have been determined using an inflow condition for the normal component of the velocity (Mellor 2003), i.e., daily baroclinic velocities from the WPO model were spatially interpolated and assigned to the open lateral boundary grids of the EAMS model. For temperature and salinity on the open boundaries, upstream advection boundary conditions were used (Mellor 2003). Advected values calculated from the WPO profiles of temperature and salinity were interpolated to the EAMS model grid. 
The EAMS model was initialized by the temperature and salinity fields of the WPO model outputs in January 1999 and was under climatological forcing for one year. After the spin-up period, the EAMS model was forced with different wind data sets to investigate the sensitivity of transport to various atmospheric wind products. The three different wind data sets are from ECMWF, the National Centers for Environmental Prediction (NCEP) (Kalnay et al. 1996), and QSCAT/NCEP (NASA Quick Scatterometer/NCEP). ECMWF products include 10 meter winds and surface stresses (6-hourly at $2.5^{\circ}$ resolution). The NCEP forcing (also 6-hourly at $2.5^{\circ}$ resolution) is a surface stress product. The blended QSCAT/NCEP wind stress data set is one of the most up-to-date high-resolution data sets of ocean surface winds at the present time. We adopted 6-hourly maps of $10 \mathrm{~m}$ zonal and meridional wind components at a resolution of $0.5^{\circ} \times 0.5^{\circ}$. The maps are derived from a space and time blend of QSCAT-DIRTH satellite scatterometer observations and NCEP analyses (Milliff et al. 1999). The EAMS model was forced by the three 6-hourly surface wind stress data sets and coupled (as described above) at the open boundaries to the WPO model. The model was then run for $1999-2003$ period. The only difference in all model experiments presented here is wind forcing.

\section{RESULTS AND DISCUSSIONS}

\subsection{Model Experiments and Validation}

To display the ocean model response to atmospheric wind forcing, three experiments EC (ECMWF), NC (NCEP) and QS (QSCAT) are conducted. Each of these experiments is initialized from the tenth-year outputs from the WPO model with identical boundary conditions, and is integrated for 5 years with three different wind forcing data sets.

As mentioned in the introduction, the observed velocities in the Taiwan Strait are limited. Figure 2a shows the only strait-wide transport data available to date (after Teague et al. 2003 and Ko et al. 2003). From October to November 1999, transport through the Taiwan Strait was measured with four bottom-mounted Acoustic Doppler Current Profilers (the locations as shown in Fig. 1b). The time series in Fig. 2a shows transport reversals at a biweekly period, possibly caused by the biweekly atmospheric winter fronts. For comparison and validation, the modelderived volume transports together with the observed transport across the Taiwan Strait are presented in Fig. 2b. Differences are significant among the three model runs. In experiment EC, all model transports are positive (northward) during the entire period. This is not consistent with the observation. On the other hand, experiments NC and QS showed five reversal events similar to the observation. Furthermore, the peak-to-peak comparison indicates that the result from experiment QS has better agreement with observations than that from experiment NC. For example, both transports from observation and experiment QS reach around $-5 \mathrm{~Sv}$ (southward) on October 17, 1999, but the corresponding volume transport in experiment NC is only around $-3 \mathrm{~Sv}$. The comparison indicates that QSCAT wind forcing produces much more realistic results and supports the existence of strong southward current bursts observed by bottom-mounted ADCPs. The occurrence of southward current bursts explains why estimates from multiple-years averages missed the southward flow. To our knowledge, this is the first time that a southward transport is produced in a numerical model without any data assimilation. 
Ko et al. (2003) also showed the existence of a southwestward flow in a model with data assimilation. Their model assimilated satellite altimeter data, Muti-Channel Sea Surface Temperature (MCSST), and the static climatology from Modular Ocean Data Assimilation System (MODAS) to produce the three-dimensional fields of temperature and salinity.
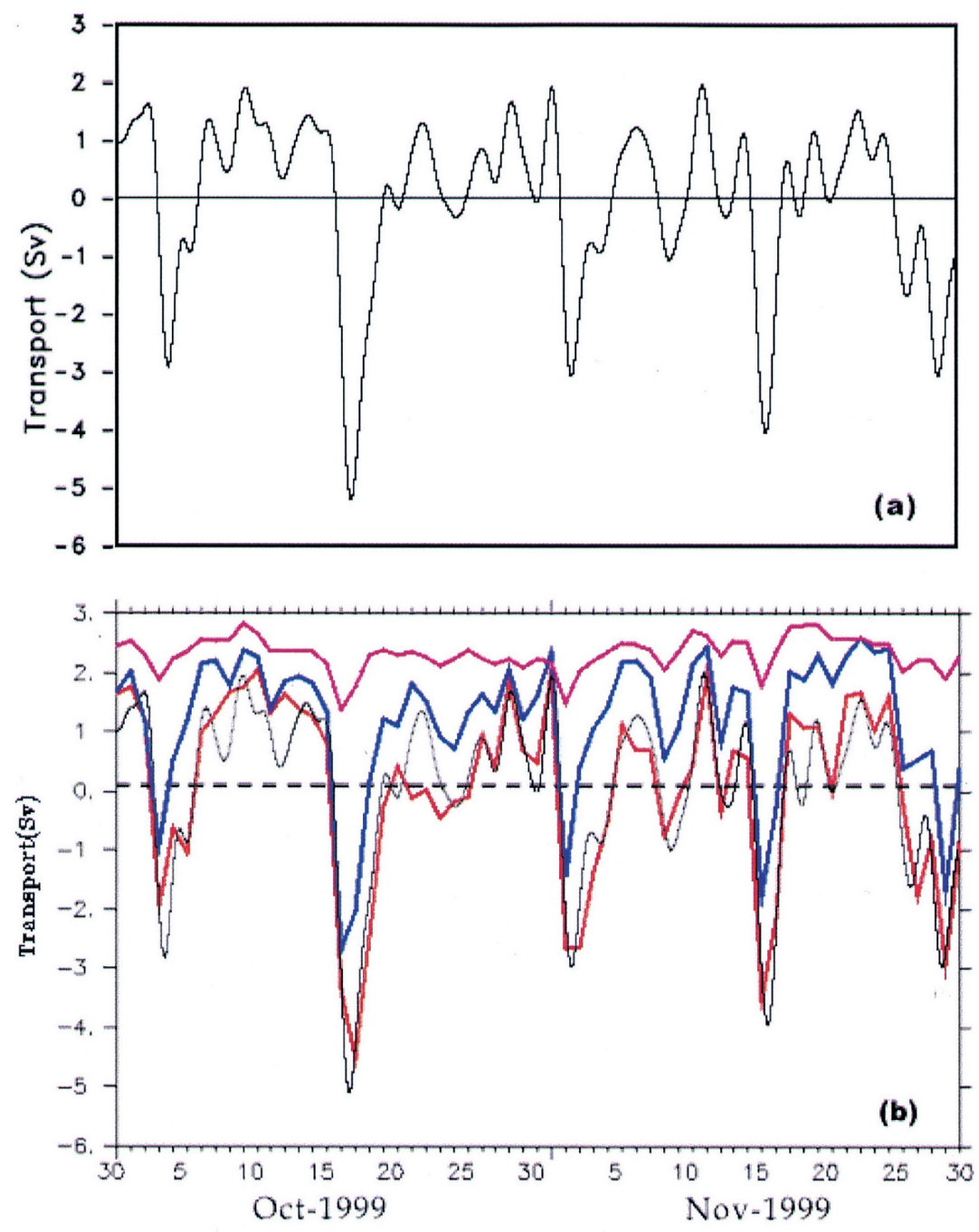

Fig. 2. (a) Transport time series through the Taiwan Strait calculated from four bottom-mounted ADCP (from Teague et al. 2003 and Ko et al. 2003). (b) The model-derived volume transports across the Taiwan Strait. Red, blue, and purple lines represent the three numerical experiments QS, NC and EC, respectively. For comparison, the observed transport is also plotted (black line). 


\subsection{Transport through the Penghu Channel}

Figure 3 shows model transport in experiment QS through the Penghu Channel. Several recent measurements are also shown for comparison. Pink segments, including $\pm 0.20 \mathrm{~Sv}$ error bars, indicate sb-ADCP measurements from Jan and Chao (2003). Model-produced transports are generally consistent with these segments. Seasonal variations are clearly evident in both the data of Jan and Chao (2003) and the present model. Largest northward transport appears in summer, and the transport is much weaker or even southward in fall and winter. The seasonal variation is consistent with the seasonal reversal of the East Asian monsoon. The optimal solution (red circle), calculated from a sb-ADCP survey on 17 20 May 1999 (Wang et al. 2004), is slightly higher than the model predicted. Wang et al. (2004) pointed out that there was a strong southerly wind burst prior to the field study and the wind burst might have increased the northward flow. Blue stars represent transports calculated from sb-ADCP observations by Dr. Ruo-Shan Tseng (unpublished data). Again, the model transports are comparable to these values.

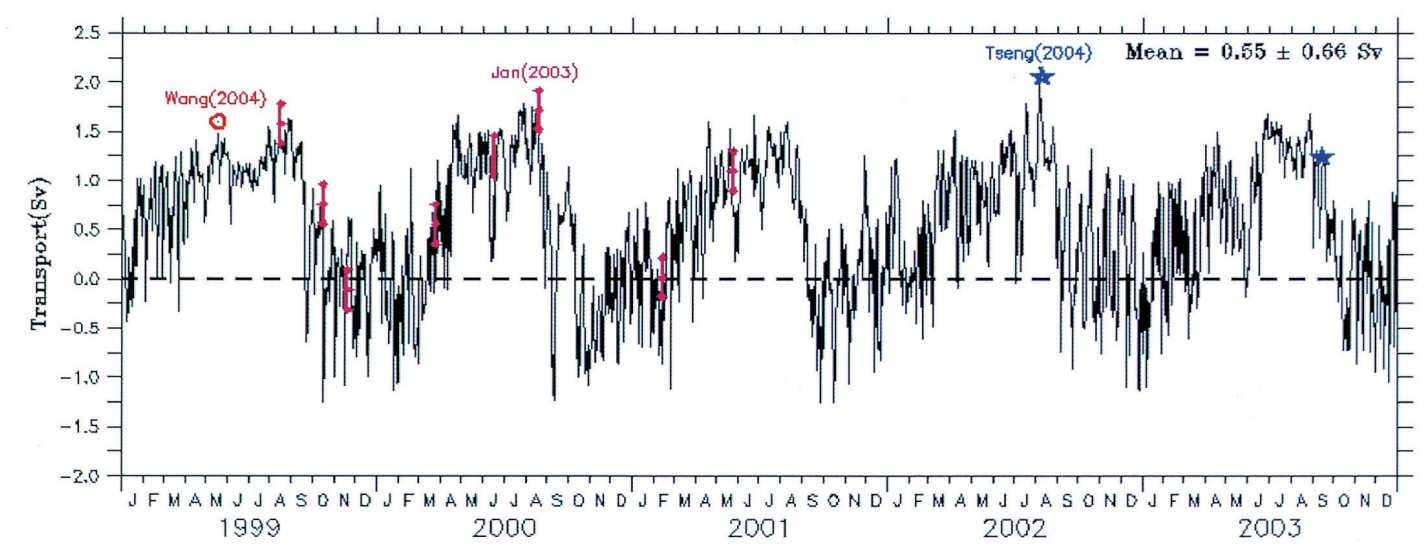

Fig. 3. Model transport compared to observations through the Penghu Channel. Pink segments and red circle are calculated from sb-ADCP measurements by Jan and Chao (2003) and Wang et al. (2004), respectively. Blue stars are calculated from sb-ADCP observations by Dr. Ruo-Shan Tseng (unpublished data).

The annual averaged transport based on the present model is $0.55 \mathrm{~Sv}$, which is significantly less than the value $0.86 \mathrm{~Sv}$ calculated from sb-ADCP measurements (Jan and Chao 2003). Bad weather often prevented seagoing operations in the Taiwan Strait and the Penghu Channel, especially during winter when the strong northeast monsoon dominated. Thus, sbADCP observations are lacking during periods when the southward flow is most likely to appear. Excluding those data points, the annual averaged transport from sb-ADCP measurements is overestimated. 
The Penghu Channel transport is modulated by the East Asian monsoon, northeasterly in winter and southwesterly in summer. The strong seasonal variation is evident in the modelproduced transport (Fig. 3). For many years, researchers have tried to provide a simple linear relationship between the transport and the along-strait wind stress. The purpose is to provide a quick estimate of the volume transport in the area using wind stress information, which is

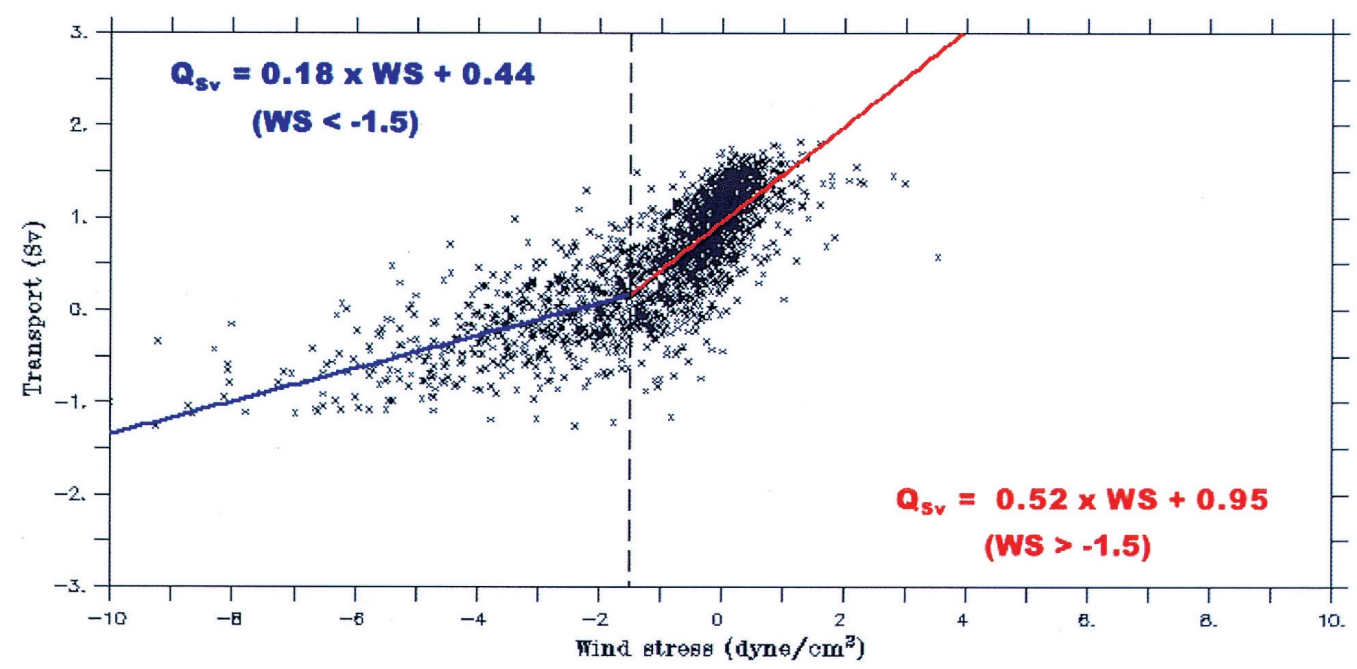

Fig. 4. Relationship between the transport through the Penghu Channel and the along-strait wind stress.

easier to acquire. Following this path, Fig. 4 compares the calculated transport with the QSCAT wind stress averaged over the Channel from $119.5^{\circ} \mathrm{E}$ to $120^{\circ} \mathrm{E}$ and from $23^{\circ} \mathrm{N}$ to $24^{\circ} \mathrm{N}$. The best fit for the transport and the local wind stress is achieved using two regression lines. One line represents the situation during strong winds $\left(<-1.5\right.$ dyne $\left.\mathrm{cm}^{-2}\right)$ and the other represents condition with weak winds $\left(>-1.5\right.$ dyne $\left.\mathrm{cm}^{-2}\right)$. The equation for the blue line (correlation coefficient $\gamma=0.92$ ) is:

Transport $(\mathrm{Sv})=0.18 \times$ wind stress $\left(\right.$ dyne $\left.\mathrm{cm}^{-2}\right)+0.44 . \quad \mathrm{WS}<-1.5$

The equation for the red line $(\gamma=0.94)$ is:

Transport $(\mathrm{Sv})=0.52$ wind stress $\left(\right.$ dyne $\left.\mathrm{cm}^{-2}\right)+0.95 . \quad$ WS $>-1.5$

In general, the blue line represents strong wind conditions that occur mostly during winter. 
On the other hand, the red line represents conditions for the rest of the year when the wind stress is weak or northward. The two regression lines show the different responses of volume transport through the Penghu Channel to wind forcing. The slope of the blue line is less than that of the red line, indicating that as the wind stress increases, transport increases much slower under strong northeasterly wind in winter than in other seasons. It is suggested that a northward pressure gradient not forced by local wind is present.

\subsection{Transport through the Taiwan Strait}

Figure 5 shows the model transport together with some limited observed transports through the Taiwan Strait. Blue stars and red circles represent strait-wide volume transports calculated from sb-ADCP observations by Dr. Ruo-Shan Tseng (unpublished data) and by Chung et al. (2001). Similar to the volume transport through the Penghu Channel, the model transports through the Taiwan Strait are comparable to the observed values. The average strait-wide transport of 1.09 Sv is about double the average transport through the Penghu Channel although the cross-sectional area of the Penghu Channel is only one-fifth of that of the Taiwan Strait. Therefore, currents are much stronger in the Penghu Channel than in the rest of the strait. The model result is consistent with the well-known statement that the Penghu Channel is the major pathway for the northward flow entering the Taiwan Strait (e.g., Wang and Chern 1988; Jan and Chao 2003).

Strong seasonal variation in Penghu Channel is evident in Fig. 5 as well. The volume transport is northward and largest in summer. It is minimum and even southward in fall and winter. The trend of the volume transport is related to the seasonal reversal of the monsoons.

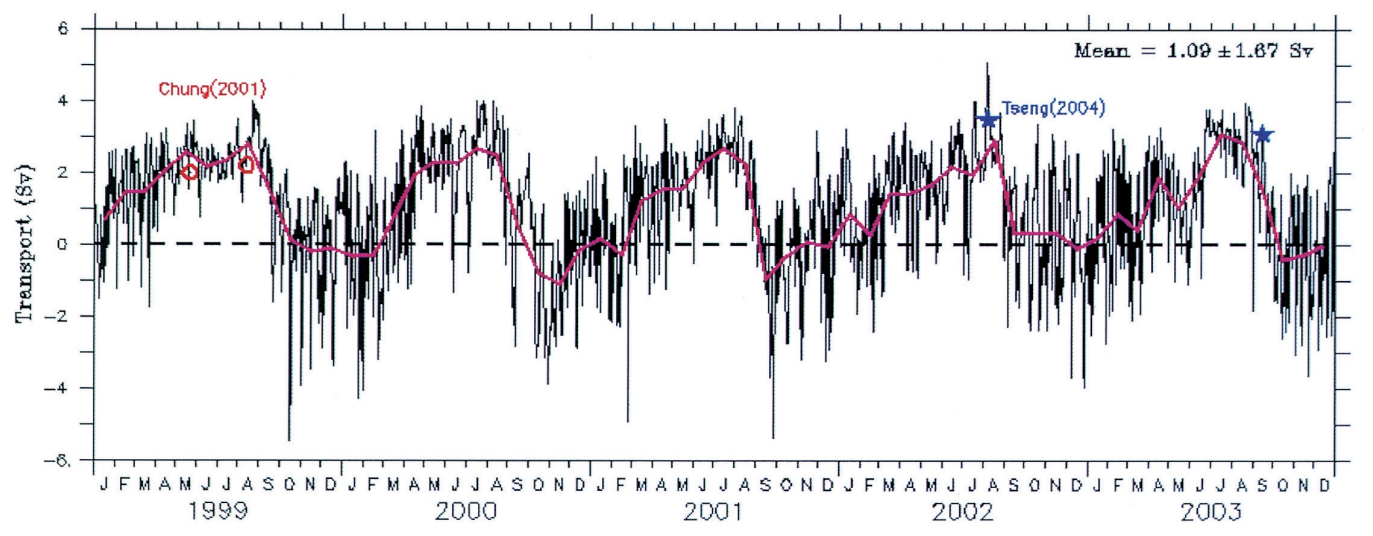

Fig. 5. Model transport and observed transports in the Taiwan Strait. Blue stars and red circles represent strait-wide volume transports calculated from sb-ADCP measurements by Dr. Ruo-Shan Tseng (unpublished data) and by Chung et al. (2001), respectively. Purple line represents monthly mean model transport. 
The occasional strong northeasterly wind bursts in fall or winter drive currents southward and produce large and negative transport up to $-5 \mathrm{~Sv}$ (Fig. 5). These events of winter fronts are seldom observed because of severe weather, but are important to balance the nutrient budget.

In addition to the seasonal variation, inter-annual variation also exists. The purple line in Fig. 5 shows the smoothed transport. The mean transport in summer 2003 is largest in the 5year period. On the other hand, southward transport is smallest in fall and winter of 2002. Furthermore, variations of volume transport in summer are much smaller than those in winter, indicating that flow conditions in the Taiwan Strait are more complex during wintertime. Several factors could account for the phenomenon, e.g., local effects of the northeast monsoon and sea level differences between the East China Sea and South China Sea. The annual average transport of $1.09 \mathrm{~Sv}$ is much smaller than most observed values, which contain uncertainties due to coarse spatial resolution and lack of winter measurements.

Figure 6 shows the relationship between volume transport through the Taiwan Strait and along-strait wind stress obtained by averaging the QSCAT wind stress in the domain from $118^{\circ} \mathrm{E}$ to $120^{\circ} \mathrm{E}$ and from $23^{\circ} \mathrm{N}$ to $25^{\circ} \mathrm{N}$. Unlike the two regression lines shown in Fig. 4, only one simple regression line suffices in the figure, and its correlation coefficient $(\gamma)$ is equal to 0.82 . The equation is:

$$
\text { Transport }(\mathrm{Sv})=1.06 \times \text { wind stress }\left(\text { dyne } \mathrm{cm}^{-2}\right)+1.99 \text {. }
$$

The volume transport is $1.99 \mathrm{~Sv}$ northward when wind stress is zero. The result suggests that the strait-wide volume transport is contributed by not only wind stress but also a northward pressure gradient force.

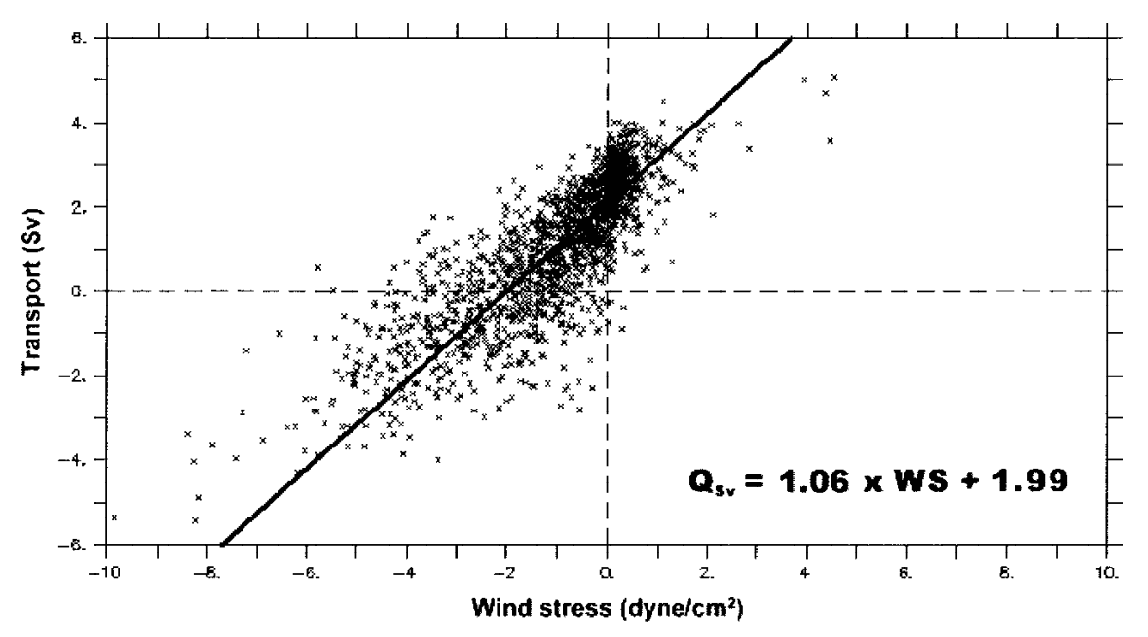

Fig. 6. Relationship between transport through the Taiwan Strait and the alongstrait wind stress. 


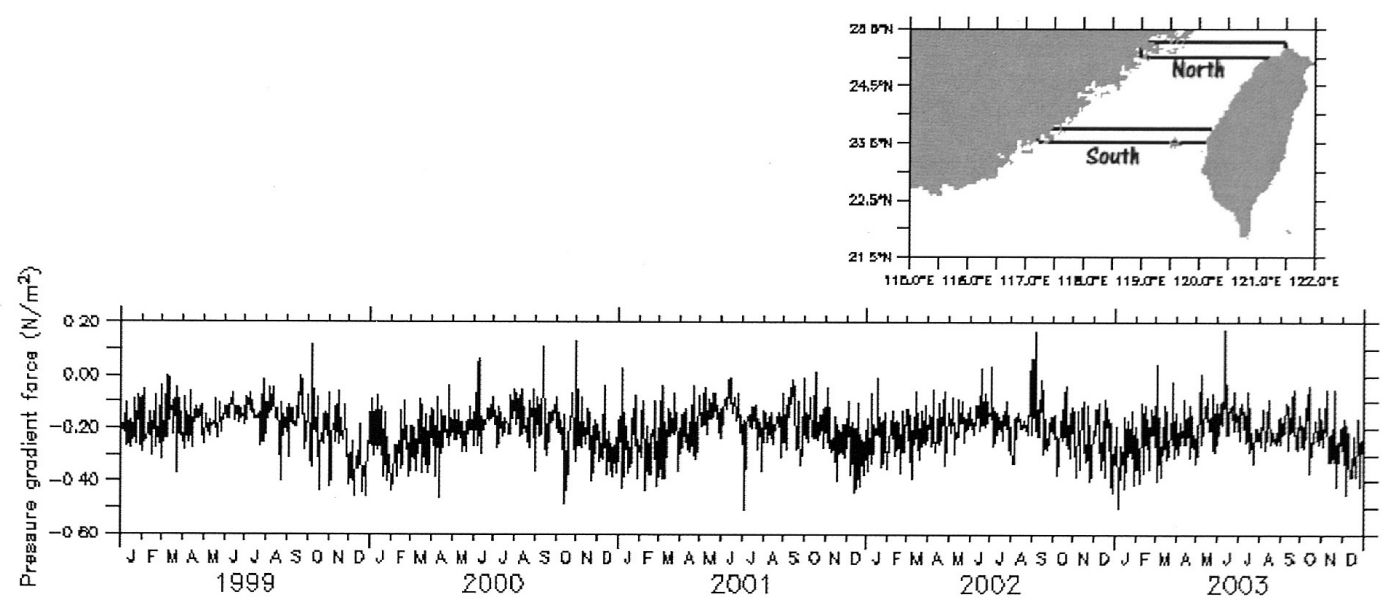

Fig. 7. Model pressure gradient force between north and south entrances of the Taiwan Strait during the period from 1999 to 2003. The pressure gradient is calculated from model sea surface height difference.

Figure 7 shows the model pressure gradient force between north and south entrances of the Taiwan Strait during the period from 1999 to 2003. The pressure gradient is calculated from model sea surface height difference. The north entrance is averaged over the domain from $119^{\circ} \mathrm{E}$ to $121.5^{\circ} \mathrm{E}$ and from $25^{\circ} \mathrm{N}$ to $25.25^{\circ} \mathrm{N}$. The south entrance is averaged over the domain from $117.25^{\circ} \mathrm{E}$ to $120.25^{\circ} \mathrm{E}$ and from $23.5^{\circ} \mathrm{N}$ to $23.75^{\circ} \mathrm{N}$. The pressure gradient is always negative because sea surface is always lower at the north entrance of the Taiwan Strait than at the south end. This pressure gradient forces a mean current northward year round and is not driven by local winds. However, the large-scale monsoon is still responsible for building up the sea level in the south. The monsoon wind field is affected by coastline, resulting in the large difference between the sea surface height in the East China Sea and South China Sea. The Kuroshio intrusion through the Luzon Strait is also a possible source of higher sea level south of the Taiwan Strait.

There is significant seasonal variation in Fig. 7. For example, the pressure gradient force is generally larger in winter than in summer. This seasonal variation of the pressure gradient force might affect the volume transport as well. However, it seems that its effect is not significant in this study. We have excluded the volume transport caused by the pressure gradient force and have done regression analysis with the along-strait wind stress. The regression line is similar to that in Fig. 6 with correlation coefficient $(\gamma)$ increasing slightly from 0.82 (Fig. 6) to 0.84 .

Chuang (1985) proposed a simple equation to describe the balance of along-channel momentum for friction dominated steady flow in a straight channel. Using the regression equation (4) as well as Chuang's (1985) equation, a resistance coefficient was estimated. An ap- 
proximate transport was thereafter calculated from the wind stress, resistance coefficient, and model sea surface height based on Chuang's simple equation. The agreement between the model transport (red line) and the approximate transport (blue line) in Fig. 8 supports the friction dominant scenario.

From Figs. 4 and 6, model transports through Taiwan Strait and PHC, respectively, are

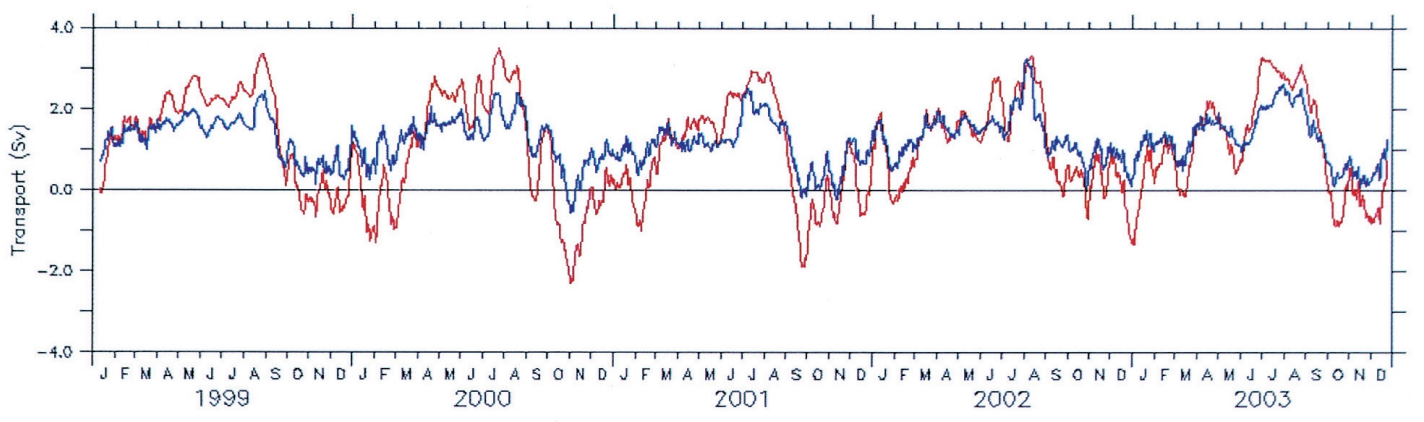

Fig. 8. Comparison between model transport (red line) and transport estimated using a resistance coefficient (blue line) during the period from 1999 to 2003.
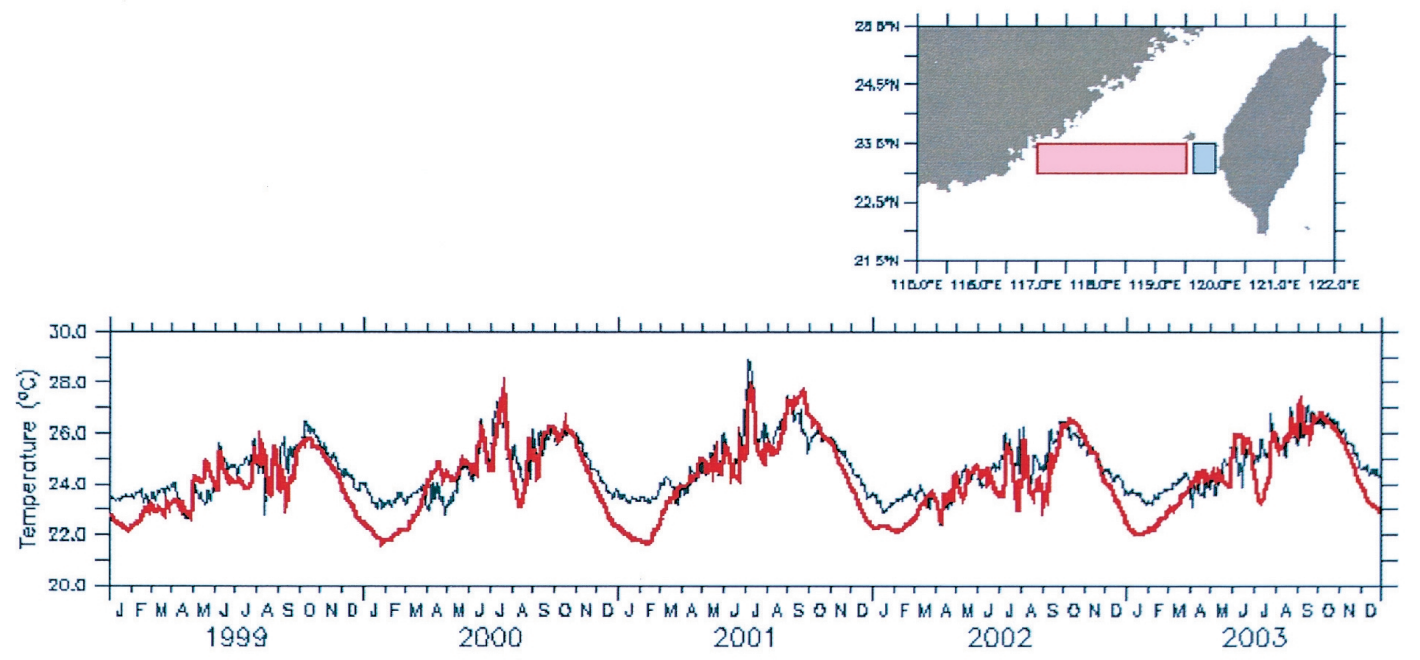

Fig. 9. Comparison of upper-layer temperatures $(0 \sim 50 \mathrm{~m})$ to the east (black line) and west (red line) of the Penghu Island during the period from 1999 to 2003. The temperatures are averaged over the regions of black and red rectangles shown in the upper panel. 
-6 and $-1 \mathrm{~Sv}$ at WS $=-8$ dyne $\mathrm{cm}^{-2}$, and are -2 and $-0.5 \mathrm{~Sv}$ at $\mathrm{WS}=-4$ dyne $\mathrm{cm}^{-2}$. The results suggest that under strong northeast monsoon, most southward transport in Taiwan Strait is to the west of Penghu Island, where the current along the coast of China transports cold coastal water southward. The model temperature distribution confirmed this statement. Figure 9 shows a comparison of upper-layer temperatures to the east and west of Penghu Island during the period from 1999 to 2003. The upper-layer temperatures were averaged vertically from surface to $50 \mathrm{~m}$ deep. All five-year data show that temperature is $1 \sim 2^{\circ} \mathrm{C}$ lower west of the Penghu Island than east of it in winter. The results are consistent with earlier observations that cold, fresh China coastal water in the western portion of the Taiwan Strait was forced southward in winter under the strong and steady northeast monsoon.

\section{CONCLUSIONS}

Most studies to date support that mean currents in the Penghu Channel are northward throughout the year, as first proposed by Chuang (1985). Southward flow in winter was shown by Teague et al. (2003) and Ko et al. (2003). The present model further shows that southward flow is possible during the period from 1999 to 2003. The speed is high during a strong northeast monsoon. Consequently, volume transport in the Taiwan Strait could be southward in winter. Model experiments also suggest that the best simulation is achieved by the QSCAT wind forcing.

The seasonal variation of the model transport in the Strait is related to the seasonal reversal of the East Asian monsoon. The annual averaged model transports through the Taiwan Strait and the Penghu Channel are northward at 1.09 Sv and 0.55 Sv, respectively. Transports calculated from sb-ADCP observations could be biased because of lack of winter measurements. Further, the model results suggest that the net transport across the strait is southward under strong northeast monsoon, with a major contribution from the western portion of the Taiwan Strait. The model temperature distribution confirms that transport in the western portion brings cold China coastal water southward under strong northeasterly wind in winter.

An innovation in this study is to use two regression lines rather than one to describe the relationship between the volume transport and wind stress in the Penghu Channel. The two regimes of wind stress clearly demonstrate the different dynamic responses of transport to wind stress and demonstrate the existence of a north-south pressure gradient force. Knowledge of volume transports through the Taiwan Strait and the Penghu Channel obtained from this study could provide understanding in mass fluxes and nutrient balance in the region. Ongoing work is to develop a Taiwan Strait model with finer horizontal resolution of $5 \mathrm{~km}$. The fine-resolution model will provide further information on the flow pattern and its characteristics in the region in the near future.

Acknowledgements The invaluable comments given by Professor J. Wang of National Taiwan University and two reviewers greatly improved both the presentation and discussion. Also thanks to Dr. Wen-Der Liang at Chinese Naval Academy for providing West Pacific Ocean model outputs. This research was supported by the National Science Council, Taiwan, ROC, under grants NSC 93-2611-M-003-002. 


\section{REFERENCES}

Blumberg, A. F., and G. L. Mellor, 1987: A description of a three-dimensional coastal ocean circulation model. In: Heaps, N.S. (Ed.), Coastal and Estuarine Sciences 4: Three Dimensional Coastal Models. AGU, Washington, DC, 1-16p.

Chen, C. T. A., 2003: Rare northward flow in the Taiwan Strait in winter: A note. Continen. Shelf Res., 23, 387-391.

Chuang, W. S., 1985: Dynamics of subtidal flow in the Taiwan Strait.J. Oceanogr., 41, 8390.

Chuang, W. S., 1986: A note on the driving mechanisms of current in the Taiwan Strait.J. Oceanogr., 42, 355-361.

Chung, S. W., S. Jan, and K. K. Liu, 2001: Nutrient fluxes through the Taiwan Strait in spring and summer 1999. J. Oceanogr., 57, 47-53.

Flather, R. A., 1976: A tidal model of the north-west European continental shelf.Memor. Soc. Royal Sci., 6, 141-164.

Huh, C. A. and C. C. Su, 1999: Sedimentation dynamics in the East China Sea elucidated from ${ }^{210} \mathrm{Pd},{ }^{137} \mathrm{Cs}$ and ${ }^{239,240} \mathrm{Pu}$. Mar. Geology, 160, 183-196.

Isobe, A., 1999: On the origin of the Tsushima Warm Current and its seasonality. Continental Shelf Res., 19, 117-133.

Jan, S. and S. Y. Chao, 2003: Seasonal variation of volume transport in the major inflow region of the Taiwan Strait: the Penghu Channel.Deep-Sea Res. II, 50, 1117-1126.

Kalnay, E., M. Kanamitsu, R. Kistler, W. Collins, D. Deaven, L. Gandin, M. Iredell, S. Saha, G. White, J. Woollen, Y. Zhu, A. Leetmma, B. Reynolds, M. Chelliah, W. Ebisuzaki, W. Higgins, J. Janowiak, K. C. Mo, C. Ropelewski, J. Wang, R. Jenne, and D. Joseph, 1996: The NCEP/NCAR 40-year reanalysis project. Bull. Am. Metor. Soc., 77, 437 471.

Ko, D. S., R. H. Preller, G. A. Jacobs, T. Y. Tang, and S. F. Lin, 2003: Transport reversals at Taiwan Strait during October and November 1999. J. Geophy. Res., 108, 3370, 10. 1029/2003JC001836.

Liang, W. D., 2002: Study of upper ocean thermal and current variation in the South China Sea. Ph. D. thesis, Inst. Oceanogr., Nat. Taiwan Univ., 127pp.

Liang, W. D., T. Y. Tang, Y. J. Yang, M. T. Ko, and W. S. Chuang, 2003: Upper-ocean currents around Taiwan. Deep-Sea Res. II, 50, 1085-1105.

Liu, K. K., T. Y. Tang, G. C. Gong, L. Y. Chen, and F. K. Shiah, 2000: Cross-shelf and alongshelf nutrient fluxes derived from flow fields and chemical hydrography observed in the southern East China Sea off northern Taiwan. Continen. Shelf Res., 20, 493-523.

Mellor, G. L., 2004: Users guide for a three-dimensional, primitive equation, numerical ocean model. Program in Atmospheric and Oceanic Sciences, Princeton University, 53pp.

Mellor, G. L., and T. Yamada, 1974: A hierarchy of turbulence closure models for planetary boundary layers. J. Atmos. Sci., 31, 1791-1806.

Mellor, G. L., and T. Yamada, 1982: Development of a turbulence closure model for geophysical fluid problems. Rev. Geophy. Space Physics, 20, 851-875. 
Milliff, R. F., W.G. Large, J. Morzel, G. Danabasoglu, and T. M. Chin, 1999: Ocean general circulation model sensitivity to forcing from scatterometer winds.J.Geophy. Res., 104, 11337-11358.

Oey, L. Y., G. L. Mellor, and R. I. Hires, 1985: A three-dimensional simulation of the HudsonRaritan estuary. Part I: Description of the model and model simulations. J. Phys. Oceanogr., 15, 1676-1692.

Teague, W. J., G. A. Jacobs, D. S. Ko, T. Y. Tang, K. I. Chang, and M. S. Suk, 2003: Connectivity of the Taiwan, Cheju, and Korea Straits. Continen. Shelf Res., 23, 63-77.

Wang, J., and C. S. Chern, 1988: On the Kuroshio branch in the Taiwan Strait during wintertime. Prog. Oceanogr., 21, 469-491.

Wang, Y. H, S. Jan, and D. P. Wang, 2003: Transports and tidal current estimates in the Taiwan Strait from shipboard ADCP observations (1999 - 2001). Estuarine Coastal Shelf Sci., 57, 193-199.

Wang, Y. H., L. Y. Chiao, K. M. M. Lwiza, and D. P. Wang, 2004: Analysis of flow at the gate of Taiwan Strait. J. Geophy. Res., 109, C02025, doi:10.1029/2003JC001937.

Wyrtki, K., 1961: Physical oceanography of the southeast Asian waters, Scientific Results of Marine Investigation of the South China Sea and the Gulf of Thailand. NAGA Report Vol. 2, Scripps Inst. Oceanogr., La Jolla, California, 195pp. 